\title{
Las mujeres en la ciencia y la tecnología
}

\author{
Women in science and technology \\ Adriana Patricia Gallego Torres ${ }^{1}$ e Isabel Torres Garay ${ }^{2}$
}

${ }^{1}$ Profesora del Doctorado Interinstitucional Universidad Distrital Francisco José de Caldas. ${ }^{2}$ Profesora del Universidad Distrital Francisco José de Caldas Bogota-Colombia. Grupo de Investigación ENCIMA. Adpgallegot@udistrital.edu.co; isagt@hotmail.com

\section{Resumen}

Es evidente que la mujer está prácticamente ausente en los libros de historia de la ciencia y la tecnología, lo mismo ocurre en los libros de texto de ciencias utilizados para la enseñanza básica y media. Este trabajo pretende reivindicar la contribución de la mujer en el desarrollo de la ciencia y la tecnología. Para ello recurriéremos a algunos ejemplos y reflexiones, que nos permitan sacar de la sombra a las mujeres cient́ficas y mostrar no solo su participación sino las dificultadas a las arales e tubo que enfrentar por su condición de género.

\section{Palabras claves}

Género, mujer, ciencia, tecología.

\section{Abstract}

It is dear that women are virtually absent in the history books of science and technology, the same is true in the science textbooks used in primary and secondary education. This study attempts to daim the contribution of women in the development of science and technology. This appealed to some examples and ideas, allowing us to get out of the shadow women in science and to show not only their participation but to the difficulties which confront tube and their gender.

\section{Keywords}

Gender, woman, science, technology.

\section{Introducción}

Este trabajo trata de evidenciar algunas de las razones por las cuales a través del tiempo no se ha dado el verdadero reconocimiento al aporte que la mujer proporcionado a la ciencia y a la tecnología.

Las cifras que hablan de la participación de la mujer en el desarrollo de la ciencia y la tecnología a través de la historia son bastante desalentadoras, son muy pocas las mujeres, científicas o tecnólogas que han logrado obtener reconocimiento. La pregunta a la que se intenta responder es básicamente: ¿Por qué hay tan pocas mujeres en la historia de la ciencia y la tecnología, será que la ciencia es cosa de hombres?

En los siglos anteriores, las mujeres estaban destinadas a la vida marital, donde sus objetivos eran: mantener la unión familiar, ocuparse de las tareas de la casa, de los hijos, etc. Los hombres las representaban ante la sociedad, siendo relegadas y aisladas. (Arango y Orduz 1998). La 
exdusión y discriminación que sufiió la mujer comenzó entre otros, al negarle el acceso a la educación, auestión que con los años seria fuente de tensiones, e induso de rechazo, ya que no era bien visto que las mujeres invadieran espacios reservados exdusivamente para el varón.

Para la mujer era inconcebible una formación generalizada y específica más allá de la necesaria para ejercer su papel de madre, hija y esposa, y para ello, ya se encargaba la misma familia, $y$ sobre todo la Iglesia, proporcionando una concepción desvirtuada de lo que debería ser una buena mujer asociado a un modelo de mujer hogareña, sumisa, ordenada, resignada... que respondía al papel que Dios y la sociedad le había encomendado: el auidado del hogar y la educación de los hijos, a lo que cabe añadir la atención de los mayores, los enfermos y los necesitados. A lo sumo, la escuela primaria colaboraría en conseguir tales fines, reforzando $y$ puliendo la misma formación secular que la mujer iba recibiendo.

La educación de la mujer se convirtió así en un asunto privado y doméstico. La madre tenía la labor de enseñar a sus hijas los saberes básicos para desarrollar las funciones propias del sexo femenino en el espacio físico y social que le había asignado la sociedad patriarcal, el hogar, en su calidad de madre, hija o esposa; a la vez que le transmitía los valores y las pautas de conducta que debían orientar su vida personal y su relación con la sociedad. Las mujeres rurales estaban destinadas a oficios como homo, la agricultura, el lavadero, etc. Por ello, si alguna mujer quería optar por la educación, no tenía mas opciones que el convento, como lo hicieron la mexicana Sor Juana Inés de la Cruz (1648 - 1695) o la granadina Sor Francisca Josefa del Castillo (1671 - 1742).

En Colombia, las mujeres tuvieron que esperar hasta la fundación pionera en 1783 del colegio de la Enseñanza en Santafé de Bogotá, promovida y financiada por doña Clemencia de Caycedo. Con ello se traía a Colombia la rica experiencia educativa de la comunidad fundada por santa Juana de Lestonnac casi dos siglos antes. En el establecimiento había una escuela pública gratuita y otra privada para pupilas que pagaban una pensión por sus alimentos y cuidado de su ropa. Al respecto dice la madre Pilar Foz: "La fecha del 23 de abril de 1783, con la apertura del pensionado-colegio y de la primera escuela pública femenina en Nueva Granada, puede calificarse de histórica. La noticia fue recibida con regocijo por los santafereños que, por primera vez, contemplaron grupos de niñas y adolescentes que se dirigían a la escuela... Un derecho, hasta entonces, reservado a los varones" (Fox y Fox, 1997). En dicho establecimiento, como lo dice el historiador de la educación Luis Bohórquez, "se formaron las madres, hermanas y esposas de los próceres". En la visita que el Libertador Simon Bolivar hizo a La Enseñanza en 1830 dejó este mensaje: "Deseo que aquí se eduquen las grandes mujeres colombianas, y que aprendan desde encender la pajuela hasta las artes y las ciencias".

La discriminación cumicular duraría hasta bien entrado el siglo XX, avando ya se habían levantado las primeras voces a favor de la igualdad de la enseñanza de la mujer, la discriminación que sufía la mujer de las dases populares ta destinada a ir a la escuela pública elemental- era mucho mayor. Hay fundados estudios que evidencian que el curriaulum real más completo de las niñas en la mayor parte de las escuelas se concretaba en leer, escribir, coser y rezar -acompañado, casi siempre, de nociones de urbanidad-. Pero aun quedaban muchas escuelas que ofrecen un curriculum más abreviado, limitado a coser $y$ rezar. Ello pone al descubierto las reticencias que todavía al finalizar el siglo XXX existen a la enseñanza de la lectura, y sobre todo la escritura, a las niñas, también la gramática, la aritmética, e induso las labores, generaban ciertas resistencias, de donde cabe decir que será rezar y coser el aurniculum nudear de las escuela de niñas en tanto respondla a la demanda básica de educación femenina. El resto de materias "propias" para la mujer, seguía siendo objeto de discusión.

La escuela pública, como hemos dicho, era una institución destinada a las niñas procedentes de las clases populares, ayya razón de ser no era ofrecer una formación 
distinta a la que venían recibiendo, sino dar una respuesta más eficaz a esa misma formación; educar no para sí mismas, sino en razón de la utilidad para la familia y para la sociedad, Las niñas y jóvenes de las clases altas en Europa reciben una educación propia a cargo de preceptores privados 0 en colegios femeninos de carácter religioso o seglar. Se trata de un barniz aultural y de algunas habilidades útiles para brillar en el ámbito social en el que desenvuelven y ayo centro es el salón: junto a la lectura, escritura, costura y bordado figuran una serie de aprendizajes adquiridos sin regularidad como geografía, historia, música, y en algunos casos, dibujo, piano, francés... que conforman lo que se llamó -frente a los conocimientos necesarios- una "educación de adomo", bien descrita en los tratados de educación de la mujer de la época:

'Cuando una joven tiene ya formado su corazón por los preceptos sólidos de la virtud; cuando su instrucción está cimentada en los conocimientos indispensables a una mediana educación, debe poseer otros que, aun auando sean de adomo, completen su cultura y la proporcionan honesta distracción en medio de sus tareas. Tales son con el baile, la música, el dibujo, los bordados y algunos otros... Así vuestro papá tiene resuelto daros (sic) esta enseñanza que pertenece a la escuela de adomo, después que conduyaís la gramática, la aritmética, la escritura, y las labores de costura" (Del Valle, 1854).

Las mujeres de la dase media, debieron resignarse a recibir una formación esmerada en colegios, semejantes a de las mujeres de dase alta, pero a diferencia de ésta no tendrá más utilidad que la que le brinda su papel doméstico. De este estrato social, sobre todo de las capas medias bajas, saldrán las primeras mujeres que busquen en estudios -mediante la obtención de las títulaciones académicas correspondientes- una medio para acceder al mundo laboral retribuido; sin ser el único camino que toma la mujer, la escuela representó la primera gran vía de integración en la economía extradoméstica con posterioridad a la revolución industrial.

Pero a pesar de todos los obstáculos, hubo mujeres que gracias a ser familiares de científicos pudieron tener instrucción académica $y$ científica $y$ se destacaron por sus inventos y sus investigaciones, pero el problema de la exdusión y la discriminación no les permitió obtener el reconocimiento que se merecáan ya que las patentes y los derechos de autor estaban destinados a los hombres quienes las representaban ante la sociedad.

\section{El problema de las patentes}

A través de la historia de las ciencias y las tecnologías, los productos de las investigaciones y sus protagonistas le pusieron nombre a las cosas que habían construido. Algunos productores inventaron símbolos o ilustraciones para identificar y distinguir sus artefactos principalmente, debido a que muchas personas no sabían leer ni escribir.

El registro de las patentes, creemos que fue uno de los problemas más grandes para las mujeres que se dedicaron a la profesión de científicas y tecnólogas, no solamente sufieron la exdusión académica, por su condición de género, sino que además tuvieron que enfrentarse a que el sistema no las reconocía. Así que la gran mayoría de sus inventos o descubrimientos, fueron patentados a nombre de sus maridos, padre o hermanos, motivo por el aual, muchas mujeres que entregaron que se dedicaron a la ciencia y la tecnología y no forman parte de la historia.

En 1790 la oficina de patentes abrió sus puertas para que cualquier persona, hombre o mujer, protegiese su invención; pero en muchos casos las mujeres no podían poseer legalmente una patente independientemente de sus maridos, padres o hermanos, ya que legalmente eran los hombres las que las representaban, por lo que mudhos inventos aparecen a nombre de sus 
maridos. Hasta 1840 solamente fueron publicadas 20 patentes de mujeres. El 15 de mayo de 1809 Mary Dixon Kies se convirtió en la primera mujer estadounidense que obtenía una patente, independientemente de su marido. Natural de Connectiaut, Kies inventó un proceso para tejer la paja con la seda, con lo que se convirtió en una gran preaursora de la industria del sombrero (Barcos y Pérez 2002).

Mas allá de las patentes, tenemos el caso de mujeres que participaron como co investigadoras con hombres y su trabajo nunca fue reconocido y en el peor de los casos sus descubrimientos se los adjudicaron otros.

Uno de los casos mas renombrado dentro de los estudios de género, es el caso Foto 51 es el nombre dado a una imagen del ADN obtenida por Rosalind Franklin mediante difracción de rayos $X$ en 1952, y que fue una evidencia fundamental para identificar la estructura del ADN. La foto fue tomada por Franklin mientras trabajaba en el King's College London, en el grupo de Sir John Randall. Maurice Wilkins mostró la foto a James D. Watson sin que Franklin lo supiera, y se convirtió en la prueba decisiva que llevó a la confirmación de la estructura doble helicoidal del ADN que había sido postulada a lo largo de 1953 en una serie de cinco artículos publicados en la revista Nature La contribución de Franklin, contribuyó a que en 1962 Watson, Crick y Wilkins, obtuvieran el premio Nobel.

Sus fotografías por difracción de rayos $X$ fueron claves para que Watson y Crick pudieran proponer el modelo de la doble hélice del ADN que les proporcionaría el Premio Nobel en 1962 junto a Maurice Willkins. Sin embargo, silenciada por la historia de la ciencia y una temprana muerte, y ridiculizada en la narración autobiográfica que Watson (1968) hace del episodio, su contribución no tuvo ningún reconocimiento (ninguno de los galardonados la recordó en la entrega de los premios, su nombre ni siquiera aparecía en las reconstrucciones en encidopedias, libros de texto y museos de ciencia...) hasta la publicación de la biografía que escribe Anne Sayre (1975), en la que se cuenta una historia muy distinta, la de la dificil situación de una científica, mujer y judía, en una institución (el King's College, de Londres) tradicionalmente masculina y daramente anglicana (Gonzáles y Pérez 2002).

Otro caso sorprendente que vale la pena resaltar es el de Ada Lovelace Byron (1815-1852), quien trabajo con el cient́fico ingles Charles Babbago en la invención de la "maquina analítica". Esto significó que el programa de programación aparecido en 1967 llevara su nombre: Ada.

Esta mujer dedicada a la tecnología, se inmersa en el mundo de las maquinas por medio de Charles Babbage, a quien se podrirá otorgar el origen de los computadores, tal y como los conocemos hoy debido a su maquina analítica. Ada se inventa un programa que permitirá pasar de la maquina analítica al computador, es decir, lo que propuso fue un computador que induía corriente, o flujo de entrada en forma de paquete de tarjetas perforadas, una memoria para guardar los datos, un procesador pasar las operaciones matemáticas y una impresora para hacer permanente el registro.

La maquina analítica hubiera sido un autentico computador digital modemo diseñada para solucionar problemas matemáticos complejos si hubiera contado con la financiación adecuada (Feldman, 1985).

Pero pese a todos sus adelantos en materia tecnológica y su buen desempeño en el equipo de trabajo, quedó relegada a un segundo plano en la mayor parte de las ocasiones como una simple transcriptora de los trabajo de Babbage. Al terminar de arreglar los errores que presentaba trabajo Ada fue prudente y consecuente con su época, pensando en que le censuraran su trabajo y cayera en el olvido por el simple hecho de ser mujer, firmo su trabajo con sus iniciales A.A.L En 1943 escribe un artículo que comenzó con una traducción de unas notas de matemático italiano L. 
F. Menabrea, donde describía y analizaba la maquina analítica o maquina de cálculo, donde induyo unas demostraciones de cómo calcular funciones trigonométricas que contuvieran variables y publicó el primer programa informático. En 1979 el departamento de defensa de los Estado Unidos creó un lenguaje de programación basada en el Pascal que llamó ADA en reconocimiento a Ada Bayron.

Otra mujer cientúfica que creemos necesario rescatar es Marie Meurdrac, quien fue una autoridad en la historia de la alquimia. Casi nada se sabe de ella, pero afortunadamente su obra publicada en Francia La Chymie charitable et facile en faveur des dames, es uno de los doce tratados de química escritos en el siglo XVII, en Europa. No se sabe la fecha de su nacimiento ni de su muerte que se cree que fue al red3dor de 1685.

La Chymie charitable et facile en faveur des dames es un libro que describe la química terapéutica del siglo XVII. En él se recoge un conjunto de recetas de medicamentos, esencias, jarabes y productos de belleza que eran de fabricación casera. El tratado tubo por lo menos cinco ediciones, tres de ellas aun se conservan en la biblioteca de Paris y dos más que se han recatado de colecciones particulares. Se encontraron también cinco ediciones en alemán y una en italiano.

Desde que Marie Curie ganara el Premio Nobel de Física en 1903, muchas han sido las mujeres científicas ċreconocidas? Esta mujer polaca inició un camino tortuoso. Su punto de partida es la Universidad parisiense de la Sorbona. Lega a ella en 1891 con su aspecto tímido y su carácter obstinado. Se refugia en el ćrculo de inmigrantes polacos. Conoce a Pierre Curie, científico francés dedicado en cuerpo y alma a la investigación científica. A los pocos meses, Pierre le pide matrimonio. Surge la unión de la ciencia.

Pronto comienzan a trabajar juntos en el fenómeno de la radioactividad. Como punto de partida tomaron los hallazgos de Antoine Henri Becquerel. Se preguntaban de dónde provenía la energía que los compuestos de uranio radian constantemente. Después de un arduo trabajo en un laboratorio destartalado e improvisado los esposos descubren los dos elementos que producáan esa radiación. A uno lo denominaron polonio y al otro radio. En 1902 el radio comenzó a existir gracias al trabajo del matrimonio Curie.

En 1903, sus hallazgos les llevan al premio Nobel de Física compartido con Antoine Henri Becquerel.

Pierre Curie ocupa la cátedra de la Facultad de Ciencias de la Sorbona, cátedra que no saboreó demasiado pues la muerte lo sorprendió. Como signo de reconocimiento, en 1906, el consejo de la Facultad de Ciencias decidió otorgar a la viuda Curie la cátedra que había desempeñado su marido. Era esta la primera vez que se concedía a una mujer tan alta posición en la universidad.

No sólo un Premio Nobel, una cátedra, reconocimiento científico, sino que Madame Curie consigue en 1911 su segundo Premio Nobel, el de Química.

Los esposos Curie no registraron la patente pues consideraron que cualquier cientíico podía buscarle aplicaciones a la radioactividad. De hecho, el radio se ha utilizado para tumores malignos. En 1911, el sexismo y la xenofobia impiden que esta gran mujer de la ciencia ingrese en la Academia de las Ciencias.

\section{Conclusiones}

Tal vez la mejor pregunta para recapitular es: ¿Cómo han hecho las mujeres, a pesar de todas las dificultades para alcanzar lugares importantes en la historia de la ciencia? Además de estos 
factores sociales y religiosos que han limitado el acceso de las mujeres al saber, hay que tener en arenta las instituciones donde se aprende y practica la ciencia. En realidad las que tuvieron la oportunidad de instruirse en casa, en los laboratorios de sus familiares tenían una ventaja, pues muchas otras no se les permitió entrar a las universidades, ni a las academias de ciencia, ni nunca fueron invitadas a presentar su trabajos en los salones o en las conferencias, ni tampoco se les permitió ejercer públicamente sus profesiones. Por otro lado las diferentes sociedades y momentos históricos han promulgado ideas muy espećficas sobre lo que significa educar a una mujer, que por lo general se traduce en el aprendizaje de las labores domésticas. Paradójicamente es en este campo donde las mujeres se han destacado en el campo de las innovaciones tecnológicas.

\section{Bibliografía}

Arango, L. y Orduz, C. (1998). Mujeres, hombres y cambio social. Editorial Lemer, Bogota

Barcos, R., y Peréz, E. (2002). Mujeres Inventoras, en línea http://inventors.about.com/ library/ blwomeninventors.htm

Del Valle, G. (1854). El espejo de las niñas. Tratado de educación moral e intelectual. Madrid, pp. 106-107.

Feldman, M. (1985) Ada, programas de computador: Editorial Reston Virginia.

Gonzales, M. y Pérez, E. (2002). Ciencia, tecología y género, Revista iberoamericana de ciencia, tecnología e innovación, numero 2

Foz y Foz, P. (1997) Mujer y Educación en Colombia. Siglos XVI - XEX Aportaciones del colegio de La Enseñanza, 1783 - 1900. Santafé de Bogotá, Academia Colombiana de Historia. 